\title{
Comparative riverscape genomics of the rainbow darter (Etheostoma caeruleum) in glaciated and unglaciated environments
}

\author{
Jon Luiken ${ }^{1}$, Tony Gamble ${ }^{2}$, and Peter Berendzen ${ }^{1}$ \\ ${ }^{1}$ University of Northern Iowa \\ ${ }^{2}$ Marquette University
}

June 4, 2021

\begin{abstract}
Periodic glaciation during the Quaternary period shaped the contemporary riverscape and distribution of freshwater fishes in the Mississippi River drainage of central North America. The rainbow darter (Etheostoma caeruleum) is a member of this ichthyofauna and has a disjunct distribution in glaciated and unglaciated environments west of the Mississippi River. The aim of this study was to utilize genome-wide SNP data to compare the population genomic structure of the rainbow darter in river networks with disparate glacial histories; the Volga River in the glaciated upper Mississippi River basin and the Meramec River in the unglaciated Ozark Plateau. Individuals were sampled from localities within each river system at distances dictated by the organismal life history and habitat preferences. Riverscape analyses were performed on three datasets: total combined localities of both rivers and one for each river independently. The results revealed a lasting influence of historic glaciation on the population genomic structure of rainbow darter populations. There was evidence of population expansion into the glaciated northern region following glacial retreat. The population genetic signature within the Volga River did not fit expectations of the stream hierarchy model, but revealed a pattern of repeated colonization and extirpation due to cyclic glaciation. The population within the unglaciated Meramec River adhered to the stream hierarchy model, with a directional order of genetic diversity based on the life history and habitat preferences of the species. These results demonstrate the necessity to consider the geologic and climatic history of a region as well as the life history of an organism when interpreting spatial genetic patterns.
\end{abstract}

Comparative riverscape genomics of the rainbow darter (Etheostoma caeruleum) in glaciated and unglaciated environments

Running title: Riverscape genomics of the rainbow darter

Jon M. Luiken ${ }^{1}$ | Tony Gamble ${ }^{2}$ | Peter B. Berendzen ${ }^{1}$

${ }^{1}$ Department of Biology, University of Northern Iowa, Cedar Falls, IA, USA

${ }^{2}$ Department of Biological Sciences, Marquette University, Milwaukee, WI, USA

Correspondence

Peter Berendzen, Department of Biology, University of Northern Iowa, Cedar Falls, IA, USA.

Email: peter.berendzen@uni.edu

\section{Funding Information}

Capacity Building Grant, Office of Research and Sponsored Programs, University of Northern Iowa; Graduate Research Award for Student Projects, College of Humanities, Arts and Sciences, University of Northern Iowa; 
Wildlife Diversity Small Grant, Iowa Department of Natural Resources.

\begin{abstract}
Periodic glaciation during the Quaternary period shaped the contemporary riverscape and distribution of freshwater fishes in the Mississippi River drainage of central North America. The rainbow darter (Etheostoma caeruleum ) is a member of this ichthyofauna and has a disjunct distribution in glaciated and unglaciated environments west of the Mississippi River. The aim of this study was to utilize genome-wide SNP data to compare the population genomic structure of the rainbow darter in river networks with disparate glacial histories; the Volga River in the glaciated upper Mississippi River basin and the Meramec River in the unglaciated Ozark Plateau. Individuals were sampled from localities within each river system at distances dictated by the organismal life history and habitat preferences. Riverscape analyses were performed on three datasets: total combined localities of both rivers and one for each river independently. The results revealed a lasting influence of historic glaciation on the population genomic structure of rainbow darter populations. There was evidence of population expansion into the glaciated northern region following glacial retreat. The population genetic signature within the Volga River did not fit expectations of the stream hierarchy model, but revealed a pattern of repeated colonization and extirpation due to cyclic glaciation. The population within the unglaciated Meramec River adhered to the stream hierarchy model, with a directional order of genetic diversity based on the life history and habitat preferences of the species. These results demonstrate the necessity to consider the geologic and climatic history of a region as well as the life history of an organism when interpreting spatial genetic patterns.
\end{abstract}

\title{
KEYWORDS
}

time-lag, Quaternary, North America, Mississippi River, Ozark Plateau, stream hierarchy model

\section{1 | INTRODUCTION}

Freshwater aquatic organisms in fluvial systems have gene flow constraints that are associated with the directional flow of water, habitat heterogeneity and the dendritic nature of the stream network. Understanding the influences on the evolution of spatial genetic structure of populations in riverine environments is a unique problem that involves a specific set of questions, which are described as riverscape genetics (Davis et al., 2018). Based on the degree of connectedness of the stream network, the distribution of habitat and life history of the organism, a directional hierarchy in genetic diversity of local populations is expected. This is referred to as the stream hierarchy model (Meffe \& Vrijenhoek, 1988). Any modification to the riverscape structure such as dams, loss of habitat, flooding or alteration of the drainage system can disrupt the patterns of gene flow and lead to changes in the expectations of the population genetic structure (Davis et al., 2018; Meffe \& Vrijenhoek, 1988).

The connectivity of stream networks and the species assemblage present within the upper Mississippi River basin of central North America are the result of a complex geologic and climatic history. Recurrent, alternating cycles of glacial advance and retreat by the Laurentide Ice Sheet during the Quaternary period, 2.6 million to 10,500 years ago, reshaped and fragmented the regional landscape and altered drainage patterns and flow regimes (Cupples \& Van Arsdale, 2014; Lowe \& Walker, 2014; Galloway et al., 2011; Knox, 2007; Figure 1). To the west of the Mississippi River, the southernmost extent of these glacial advances occurred during the Pre-Illinoian Glacial Stage (2.6 - 0.3 million years ago), reaching the present-day Missouri River valley in central Missouri (Burr \& Page, 1986; Hobbs, 1999; Thornbury, 1965; Figure 1). The Ozark Plateau and associated stream networks to the south of the Missouri River remained relatively unaffected by the glacial disturbances (Pflieger, 1975).

The distribution of aquatic species in central North America was notably affected by the habitat changes in the north, resulting in displacement or extirpation of local populations (Berendzen et al., 2010; Burr \& Page, 1986). As glacial fronts expanded and retreated the riverscape was dramatically altered causing changes to the drainage pattern, flow regime and habitat (Thornbury, 1965). West of the Mississippi River, the Ozark Plateau provided a refugium for many fish species during the periodic glacial advances of the Quaternary 
period (Berendzen et al., 2003; Berendzen et al., 2010; Burr \& Page, 1986; Echelle et al., 2014; Near et al., 2001). Following the retreat of the last glacial maximum (19,000 to 10,500 years ago), new dispersal opportunities were created among the newly formed stream connections, which contributed to the expansion of populations northward and the establishment of the contemporary fish assemblage (Berendzen et al., 2010; Burr \& Page, 1986; Ray et al., 2006).

Etheostoma caeruleum, the rainbow darter, is a member of this assemblage with a broad distribution in small rivers, creeks, and streams in the Mississippi River drainage across eastern North America (Ray et al., 2006; Strange \& Burr, 1997; Figure 2). The species is a small, sexually dimorphic fish that displays a preference for shallow, fast-flowing water within gravel or rubble riffles (Harding et al., 1998; Mueller et al., 2020). Mature individuals exhibit high site-fidelity to their natal habitats throughout their life cycle, with breeding males migrating up to $1 \mathrm{~km}$ during spring spawning periods (Hicks \& Servos, 2017). The rainbow darter is a benthic invertivore that actively forages for a variety of macroinvertebrates that inhabit riffles. Their preferred food sources are much less abundant in the deeper pools separating riffle structures (Mueller et al., 2020). In addition, E. caeruleum is considered a sentinel species and is relatively sensitive to habitat and water quality changes due to channel siltation, chemical runoff, and related effects of anthropogenic activity (Haponski et al., 2009; Tonnis, 2006).

West of the Mississippi River, E. caeruleum has a disjunct distribution inhabiting streams in the upper Mississippi River basin and the Ozark Plateau, but is absent in the intervening region (Figure 2). In tributaries of the upper Mississippi River, local populations of the rainbow darter have a patchy, disjunct distribution across the riverscape (Davis et al., 2015). Areas of local concentration are often separated by large river distances. This pattern results from the direct impact of glacial processes on the landscape causing the spatial distribution of suitable habitat to be highly fragmented and heterogeneous. Modern river drainages in this region, flow through varying depths of glacial drift overlaying the Tertiary bedrock topography (Burr \& Page, 1986; Thornbury, 1965). In contrast, the drainage patterns of the Ozark Plateau have maintained their basic configuration since the late Paleozoic era (Pflieger, 1975). Modern river drainages in this region are characterized by clear, cool high gradient streams with course substrate in deeply dissected valleys (Pflieger, 1975; Thornbury, 1965). Local populations of the rainbow darter in this region are widespread and nearly continuous, resulting from the abundant distribution of suitable habitat. The rainbow darter is one of the most abundant fish species in the Ozarks (Pflieger, 1975).

In this study we compare the fine-scale population genetic structure of rainbow darter populations in two similar river systems, one located in the glaciated environment of the upper Mississippi River basin and one in the unglaciated environment of the Ozark Plateau. We test the hypothesis that climatic and geologic processes during the Quaternary period influenced the observed genetic signature and disrupted expectations under riverscape genetic models. Under the stream hierarchy model, the population genetic structure is consistent with the structure of the stream network, distance between local populations, connectedness of the habitat and life history of the organism (Brauer et al., 2018; Meffe \& Vrijenhoek, 1988). Since the rainbow darter exhibits high site fidelity and short dispersal distances, the expectation is that local populations will be partially isolated with limited geneflow and evidence of isolation by distance in an upstream to downstream pattern. We predict that the population genetic structure of E. caeruleumin the glaciated environment in the North will not fit expectations under the stream hierarchy model and will exhibit low levels of genetic diversity. Conversely, we predict that the population genetic structure of E. caeruleum in the unglaciated environment in the South will fit expectations under the stream hierarchy model and exhibit higher levels of genetic diversity. In this study, we utilize genome-wide SNPs generated using RADseq to infer fine-scale population genetic structure in each river system.

\section{2 | METHODS}

\section{1 | Study Region and Sampling Methods}

The Volga (Fayette County, IA) and Meramec (Crawford/Dent Counties, MO) rivers were selected as systems for comparison. Both waterways are historically known to contain abundant resident populations of $E$. 
caeruleum and have segments that are relatively undisturbed and unimpeded (Davis et al., 2015; Ray et al., 2006). The Volga River is a tributary of the upper Mississippi River within the previously glaciated region of North Central North America. The Meramec River, in contrast, is a tributary of the Mississippi River traversing land within the historically unglaciated Ozark Plateau. Both systems are located to the west of the Mississippi River (Figure 2).

Local populations in each river system were sampled from riffle sites separated by at least $2 \mathrm{~km}$ of river distance (Figure 2). This distance was chosen because of the notable high site-fidelity exhibited by E. caeruleum individuals (Hicks \& Servos, 2017). Candidate segments and sampling localities in both rivers were identified using freely available GIS data in combination with satellite imagery from Google Earth. This was done to ensure adequate accessibility to each location and a lack of artificial barriers such as low-head dams within the sampling areas. A total of 10 E. caeruleum individuals were collected from each locality using kickseining techniques and backpack electrofishing where permitted. Pectoral fin tissue was taken from the right side of positively identified fish and stored in $95 \%$ ethanol for DNA work; whole specimens were preserved in formalin as vouchers and deposited at the Bell Museum of Natural History Fish collection, University of Minnesota (Table S1).

\section{2 | DNA sequencing and SNP genotyping}

A reduced representation genomic dataset using RADseq was generated to genotype all individuals using genome-wide SNPs. RADseq libraries were prepared using a protocol modified from Etter et al. (2011), as specified in Gamble et al. (2015). Genomic DNA was extracted from ethanol preserved pectoral fin clips using a DNeasy Blood and Tissue Kit (Qiagen). Approximately $1 \mu \mathrm{g}$ of DNA from each sample was digested at 37 for 2 hours using the high-fidelity SbfI restriction enzyme (New England Biolabs). A two-adapter process was utilized to create DNA libraries from the digested samples, with 10-15 individually barcoded samples allocated to each Illumina library pool. P1 adapters with unique barcodes were ligated to the specific SbfI overhang sequence exposed during the digestion process. Samples were then pooled, sheared using a sequence of cyclic sonication (Diagenode Bioruptor), and size-selected into approximately 300-400 base pair (bp) lengths using magnetic beads in PEG/NaCl buffer (Rohland \& Reich, 2012). The libraries were blunt-end repaired and dA-tailed. P2 adapters were then ligated to each pooled library to provide unique Illumina identifiers and additional barcode sequences, necessary for the Illumina sequencing process (Andrews et al., 2016). All libraries were amplified via PCR using Q5 DNA polymerase (New England Biolabs) for 14 cycles, cleaned, and size-selected an additional time using a GeneRead Size Selection Kit (Qiagen). Genomic libraries were quantified using a Qubit fluorometer and pooled for Illumina sequencing. DNA fragment sizes were verified using a Bioanalyzer assay (Agilent) and the pooled libraries were sequenced with paired-end 75 and 100 bp reads on Illumina HiSeq 4000 (75 bp paired-end) and NovaSeq 6000 (100 bp paired-end) platforms at the Genomics Division of the Iowa Institute of Human Genetics, University of Iowa.

Raw Illumina sequence data were de-multiplexed and filtered by their adapter sequences using the processradtags command inSTACKS v.2.54 (Catchen et al., 2013). Two mismatches were allowed within the adapter sequences '-adapter_mm 2 ' and any reads marked as failures by Illumina's purity filter were discarded by using the '-filter_illumina' options. The program flags, '-c ', '- $q$ ', and ' $-r$ ' were utilized to remove data with uncalled bases, low phred33 quality scores, and recover and repair barcode segments (Rochette et al., 2019). Read lengths for all samples were trimmed to a $70 \mathrm{bp}$ length to provide data continuity between both Illumina sequencing platforms and to remove any low-quality bases from the 5' end of reads (Catchen et al., 2011). Files output fromprocess_radtags were then concatenated to a single file named for each respective sample (Rochette \& Catchen, 2017).

Due to the lack of an available reference genome for E. caeruleum, the denovo_map.pl script (STACKS ) was run to create a consensus sequence catalog, generate SNP loci, and formulate candidate alleles for individual fish (Catchen et al., 2011). Parameters for the assembly process were optimized using testing procedures described in Paris et al. (2017). The minimum depth of coverage required to create a stack, a set of short-reads which match exactly, was set to a value of $3^{\prime}-m 3^{\prime}$ '. The maximum distance allowed between 
stacks was set to 3 nucleotides ' $-M$ 3' while the mismatches allowed between sample loci during catalog sequence assembly was set at 2 ' $-n 2$ '. The '-rm-pcr-duplicates' program flag was also applied to reduce the effect of PCR amplification bias by removing pairs of reads with the same insert length.

Three datasets were generated following the de novo assembly process, one for both river systems combined, and two to analyze the Volga and Meramec river data independently. For each of the datasets, the ' $-r-0.80$

' flag was implemented for the populationscommand (STACKS ) as an optimization target and filtering step to ensure only SNP loci shared by a minimum of $80 \%$ of all individuals in a population are retained (Rochette \& Catchen, 2017). The '-write-single-snp' program flag was additionally applied to restrict the analysis to the first SNP per locus and lessen the potential for error created by linkage disequilibrium. Finally, a minor allele frequency cutoff of $1 \%$ was applied with '-min-maf 0.01 ' to filter and remove potential outlier loci. Supplementary program options for the populations function were used concurrently to generate values for differentiation among sampling localities in expected and observed levels of heterozygosity, private alleles, nucleotide diversity, and inbreeding coefficients (Rochette \& Catchen, 2017). The software package PGDSpider 2.1.1.5 was used for additional conversion and formatting of the populations output (Lischer \& Excoffier, 2012).

\section{3 | Population genomics}

To identify and characterize genetic clusters within the combined river dataset, and within the river-only datasets, two methods were used for comparison: a Bayesian assignment test and a discriminant analysis of principal components (DAPC). The Bayesian assignment test was performed using the software package fastStructure (Raj et al., 2014). DAPC analyses were run using the adegenet package for R (Jombart, 2008; Jombart et al., 2010).

Large modern SNP datasets can impose challenging computational requirements in time and processing power. The software packagefastStructure makes use of efficient algorithms to employ a Bayesian framework model for the inference of the total genetic clusters $(\mathrm{K})$ within the data, and assignments of fish to a cluster based on individual genotypes without a priori definitions (Falush et al., 2007; Hubisz et al., 2009; Pritchard et al., 2000; Raj et al., 2014). The range of potential $\mathrm{K}$ values chosen included a value one above the total number of sampling localities within each dataset (Pritchard et al., 2000). K values $=1-11$ were analyzed for the combined river dataset, and $\mathrm{K}=1-6$ for each river separately. Additional parameters used for fastStructure included ' $-c v=500$ ' which enabled cross-validation over 500 test runs. The supplemental programStructure_threader was used to decrease the overall processing time required by fastStructure by the automation and parallelization of runs upon multiple CPU processing threads (Pina-Martins et al., 2017). Structure_threader also automated the identification of the most appropriate K value for each dataset using the fastStructure chooseK.py script to pinpoint the value of $\mathrm{K}$ that maximizes marginal likelihood (Raj et al. 2014). Visualizations and plotting of population memberships and admixture fromfastStructure outputs were completed using Distruct v.2.3(Chhatre, 2019).

A DAPC identifies differences between groups through discriminant functions (Jombart et al., 2010). The sampling localities within each river system were used as the groups in this test. A DAPC analysis can be substantially affected by the selection of user-defined numbers of principal components (PC) to preserve. The find.clusters andxvalDapc functions within the $\mathrm{R}$ package adegenet provided a procedure for effective cross-validation and optimization to identify the number of PCs to keep for each dataset (Jombart \& Collins, 2015). The number of PCs retained for each analysis was therefore selected by using the value of primary components with the lowest root mean squared error (RMSE) after 100 iterations per PC values of $1-100$ for the combined dataset, and values 1 - 50 for each independent river system.

Pairwise $\mathrm{F}_{\mathrm{ST}}$ values between all localities within each dataset were calculated as described in Weir \& Cockerham (1984) using the hierfstat package for the R platform (Goudet, 2005; R Development Core Team 2020). An analysis of isolation by distance was conducted for the Volga-only and Meramec-only datasets using a Mantel test. Pairwise $F_{S T}$ values were linearized $\left(F_{S T} / 1-F_{S T}\right)$ following Rousset (1997) and river distance measures were used. The Mantel test was conducted with 100,000 replicates in the $\mathrm{R}$ package ade4 (Dray 
\& Dufour, 2007). Finally, a nested analysis of molecular variance (AMOVA) was performed for each of the three datasets to further determine the spatial structure of genetic diversity. The analyses were performed using Arlequin v.3.5.2.2 (Excoffier \& Lischer, 2010).

\section{3 | Results}

\subsection{Sequencing quality, SNP loci and genetic diversity}

Over 817 million 70 bp reads were generated, with an average of 8,171,812 reads per individual after demultiplexing and length trimming. Individuals Ec641 and Ec642 from the Volga River V01 sampling locality were removed due to low sequencing coverage. The coverage for all remaining individuals ranged from $10.61 \mathrm{x}$ to $20.53 \mathrm{x}$. A total of $6,555,128$ loci were retained for genotyping, resulting in 1,405,998 variant sites among all individuals.

The combined river dataset, which incorporated all ten sampling locations in both the Volga and Meramec rivers, produced a mean of 30,236 variant SNP loci per locality (Table 1A). The overall average number of private alleles detected among SNP loci across the sampled localities was 1,673. Localities within the Meramec River exhibited a higher average number of private alleles, 2,191, in comparison to the Volga River localities, 1,154 (Table 1A). The Meramec River localities also exhibited greater genetic diversity $\left(\mathrm{H}_{\mathrm{O}}\right.$ and $\left.\Pi\right)$ than the Volga River localities. Localities V01 and MO3 had a larger number of private alleles as compared to the number observed in other localities within each river system (Table 1A). However, the measurements of genetic diversity for both localities were more similar to the values observed in the other localities within each system.

Within the Volga-only dataset, an average of 16,410 variant SNP loci were identified among the five sampled localities with an average of 1,626 private alleles (Table 1B). The genetic diversity estimates for the localities based on this dataset were much higher than those observed in the combined river dataset. Locality V01 again had a substantially higher number of private alleles with a total of 3,496 (Table 1B). However, again the diversity estimates for VO1 were similar to the values observed in the other Volga River localities (Table 1B). The Meramec-only dataset had an average of 27,061 SNP loci across the five localities, with an average of 2,424 private alleles (Table 1C). The diversity estimates in this dataset were higher than observed in the combined river dataset, but not as great of a difference as observed in the Volga River. Again, locality MO3 had the greatest number of private alleles, but had estimates of genetic diversity that were more similar to the other Meramec River localities.

There was no evidence of inbreeding in any of the datasets (Table 1). The variation in the number of SNP loci, private allele counts and genetic diversity estimates between the combined and independent river datasets is attributed to the STACKS populations ' $-r$ 0.80' flag. The command dictated the inclusion of loci only when present within $80 \%$ of individuals and therefore was dependent on the localities specified during the generation of the datasets.

\subsection{Population genomics}

The Bayesian assignment test identified an optimal genetic clustering value of $\mathrm{K}=4$ for the combined river dataset (Figure 3A). The most common cluster was observed exclusively in four Volga River localities (VO1, VO3, VO4, and VO5) and one Meramec River locality (MO2). The latter cluster was also admixed in all the remaining localities. The Volga River exhibited some population substructure with individuals from locality VO2 contained in a unique cluster with some admixture. There was greater substructure in the Meramec River with two distinct clusters observed in localities MO1, MO3, MO4 and MO5 with some admixture.

The Volga-only dataset had an optimal genetic cluster size of $\mathrm{K}=4$ (Figure 3B). A greater amount of population substructure was observed in this dataset as compared to the combined river dataset (Figure 3A). Localities VO1, VO4 and VO5 represented unique clusters with no admixture. Locality VO3 was represented by the same genetic cluster as locality VO4 with one individual exhibiting admixture. Locality VO2 was again represented by a unique genetic cluster with some admixture. The Meramec-only dataset had an optimal genetic cluster size of $\mathrm{K}=3$ (Figure 3C). Localities MO2, MO4 and MO5 contained individuals 
from the same genetic cluster with no admixture. Localities MO1 and MO3 were represented by unique clusters with some admixture.

The DAPC cross-validation functions determined PC counts with the lowest RMSE to be PC $=30$ for the combined river, $\mathrm{PC}=35$ for the Volga-only, and $\mathrm{PC}=25$ for the Meramec-only datasets. The DAPC conducted for the combined river dataset supports a genetic distinction between the Volga and Meramec river populations (Figure 4A). The Meramec River localities displayed a higher amount of distinct genetic clustering than observed within the Volga River. Within the Meramec, locality MO3 was the most distinct and localities MO2 and MO4 were the most similar with some overlap. Within the Volga River, individuals clustered by locality, but the clusters were closely associated and overlapping. Locality VO1 was the most distinct. The results of the DAPC for the Volga-only dataset was somewhat similar to the combined river dataset (Figure 4B). Individuals clustered by locality but there was a high degree of overlap among localities VO2, VO3 and VO5. Locality VO4 displayed a greater distinction from the other localities as compared to the combined dataset and locality VO1 was again the most distinct. The results of the DAPC for the Meramec-only dataset again displayed individuals clustered by locality but with less genetic distinction (Figure 4C). Localities MO2, MO3, and MO4 displayed a high degree of overlap. Localities MO1 and MO5 formed distinct clusters with greater genetic diversity. Along the scatterplot, localities are arranged in an upstream (MO1) to down downstream (MO5) order.

Measures of the pairwise $\mathrm{F}_{\mathrm{ST}}$ (WC84) among all ten localities in the combined river dataset showed a substantial amount of genetic distance between the Meramec and Volga river localities with values ranging between $0.2585-0.3560$ and an average of 0.3276 (Table S2). However, the variance between localities within each river system was small but similar in both systems. The range of values in the Volga River was 0.0005 -0.0078 with an average of 0.0038 , and the range of values in the Meramec River was $0.0000-0.0062$ with an average of 0.0019 . In the river-only datasets the pairwise $\mathrm{F}_{\mathrm{ST}}$ values were small and nearly identical to the observations in the combined river dataset (Table S3).

For the Volga-only dataset there was no evidence of IBD with no significant correlation between in-river distances and linearized $\mathrm{F}_{\mathrm{ST}}$ values $\left(\mathrm{p}=0.259, \mathrm{R}^{2}=0.245\right.$; Figure $\left.5 \mathrm{~A}\right)$. However, for the Meramec-only dataset there was evidence of IBD. There was a significant correlation between in-river distances and linearized $\mathrm{F}_{\mathrm{ST}}$ values $\left(\mathrm{p}=0.015, \mathrm{R}^{2}=0.904\right.$; Figure $\left.5 \mathrm{~B}\right)$. The results of the AMOVA test on the combined river dataset revealed the genetic variation observed is explained by both differences among river systems and differences among individuals within the same locality (Table 2A). The AMOVA tests on the independent river system

datasets also revealed that very little of the variation is explained by differences between localities. Most of the variation is explained by differences among individuals within localities (Table 2B, C).

\section{4 | Discussion}

The results of this study support the hypothesis that historical glacial cycles during the Quaternary period influenced the observed genetic signature of rainbow darter populations in drainages of central North America. They support the prediction that populations in glaciated drainages in the North do not fit expectations under the stream hierarchy model, whereas populations in the unglaciated South do. The pattern observed within the Volga River in the upper Mississippi River basin reflects recurrent extirpation and recolonization of $E$. caeruleum into the region caused by a disruption in the riverscape by repeated glacial advance and retreat. In contrast, the pattern observed within the Meramec River in the Ozark Plateau strongly adhered to the stream hierarchy model. This region was not directly impacted by glacial advances and the age and relative stability of the habitat and drainage patterns allowed for populations of E. caeruleum to persist uninterrupted. The observed genetic signature of the southern population was shaped by the life history and habitat preferences of the species rather than cycles of geologic and climatic disturbance.

\subsection{Colonization of the upper Mississippi River basin}

Analyses of the combined river dataset revealed a signature of expansion of populations into the glaciated riverscape of the upper Mississippi River basin. Even though the study sites were chosen for comparison due to their similarity in habitat and lack of obvious barriers to dispersal, they revealed different patterns 
of spatial genetic structure. The northern population in the Volga River (Figure 2) exhibited low genetic diversity (Table 1A) and little population substructure (Figures 3A, 4A). In contrast, the southern Ozark Plateau population in the Meramec River exhibited greater genetic diversity and increased population substructure. The predominant genetic cluster observed in the North is also present in the more diverse and admixed population in the South (Figure 3A). Both the AMOVA (Table 2A) and $\mathrm{F}_{\mathrm{ST}}$ (Table S2) results indicated the greatest sources of genetic variation are between the northern and southern populations.

The conclusion of expansion to the North from a southern refugium in the Ozark Plateau following glacial retreat is consistent with a range-wide phylogeographic study of E. caeruleum based on mtDNA sequence data (Ray et al., 2006). This pattern has also been repeatedly observed in other fishes within the region that also exhibit a similar disjunct distribution west of the Mississippi River. Phylogeographic studies of the Ozark minnow (Notropis nubilus ; Berendzen et al., 2010), gilt darter (Percina evides ; Near et al., 2001), Carmine shiner (Notropis percobromus ; Berendzen et al., 2008) and northern hogsucker (Hypentelium nigricans ; Berendzen et al., 2003) revealed shallow genetic divergences and lack of geographic structure between the northern and southern populations. It is hypothesized that populations of fishes expanded northward either during the Sangamon interglacial period between 125,000 - 75,000 years ago or following the last glacial maximum 19,000 to 10,500 years ago (Berendzen et al., 2010; Near et al., 2001).

This repeated pattern supports the influence of periodic glaciation during the Quaternary Period on shaping the distribution of the contemporary fish assemblage in the upper Mississippi River basin. As ice sheets retreated, populations of freshwater fishes expanded northward out of an Ozarkian refugium into suitable habitat in the upper Mississippi River basin (Berendzen et al., 2010; Burr \& Page, 1986). Following colonization of the region, contemporary populations in the North became isolated from Ozark Plateau due to the loss of suitable habitat in the intervening region. The aquatic habitat and flow regime of river systems flowing through southern Iowa and northern Missouri were altered during the mid-Pleistocene interglacial periods between the Pre-Illinoian and Illinoian Glacial Stages, 500,000 - 300,000 years ago (Anderson, 1998; Bettis, 1989; Elfrink \& Siemens, 1998). As the ice sheet retreated, immense volumes of glacial melt carried large quantities of fine-grained sediments to the alluvial plains adjacent to the Mississippi River which led to extensive aeolian loess accumulation throughout the Southern Iowa and Northern Missouri Drift Plain (Forman et al., 1992; Anderson, 1998; Young \& Hammer, 2000; Muhs et al., 2018; Pflieger, 1975). This resulted in changes to the clarity and siltation of rivers in this region and eliminated habitat for E. caeruleum and other species with similar preferences.

\subsection{Historical range contraction and expansion}

Analyses of the Volga River only dataset revealed a spatial distribution of genetic diversity that does not fit expectations under the stream hierarchy model. Local populations exhibited low diversity (Table 1B) and lack any discernable pattern of population substructure that reflects the distribution (Figures 3B, 4B). In contrast to the combined river dataset, the Volga only dataset revealed a greater number of genetic clusters with the most upstream (VO1) and downstream (VO5) localities representing unique clusters with no admixed individuals (Figure 3B). However, there was no evidence of isolation by distance (Figure 5A). The $\mathrm{F}_{\mathrm{ST}}$ values (Table S3A) indicated locality VO1 was the most genetically distinct; it contained an unusually high number of private alleles (Table 1B) as compared to the other localities. In addition, localities VO2 and VO3 are more similar to the most downstream locality, VO5, than the intervening locality VO4. The greatest sources of variation are differences among individuals within populations (Table 2B).

There are two possible explanations for the genetic signature observed in the Volga River: fragmentation of local populations due to isolation or historical range contractions and expansion. It is possible that the local populations are fragmented. The Volga River flows through a highly impacted landscape that has been dramatically altered by intensive agricultural activities and urbanization. Rivers and streams have been heavily impacted, causing extensive modification to habitat structure, water quality, and flow regime (Menzel, 1983; Knox, 2007). However, the spatial pattern of genetic diversity is random and does not fit expectations for fragmentation and isolation. In addition, the pattern does not make sense given the life history of the fish and the distribution of localities within the system. 
The best explanation is this pattern results from the influence of historical range contractions and expansions during periodic glacial cycles. There is low overall genetic diversity in the Volga River only dataset, which is reflected in the lower number of variant loci and private alleles as compared to the population in the South (Table 1B). In addition, the observed heterozygosities are relatively high with low $\mathrm{F}_{\text {IS }}$ values, which are consistent across sampled localities within the system. These observations suggest that the population in the Volga River is not in equilibrium; the observed genetic signature is not reflective of the contemporary demographic and evolutionary processes (Whitlock \& McCauley,1990; Epps \& Keyghobodi, 2015). Rather, the pattern observed is a function of the founding events that established populations in the North. The bottleneck caused by the founder effect reduces variation, but can have little effect on the observed heterozygosity (Allendorf \& Luikart, 2007). This is especially true when a population returns to a large size relatively quickly, which is consistent with the life history of E. caeruleum . Even though populations can be isolated, the rainbow darter tends to be very abundant and one the most common fish in a stream (Page, 2000).

The disconnect between the contemporary landscape and the observed genetic pattern is the result of a time-lag (Epps \& Keyghobadi, 2015). Even though it has been 10,500 years since the retreat of the last glacial maximum, a genetic signature of expansion persists. Following a major population disturbance, it takes time for genetic variation to reach equilibrium, which is determined by a number of factors including generation time, dispersal rates, effective population size and population growth rates (Epps \& Keyghobadi, 2015). Based on the complex interactions of these factors, it can take tens of thousands of generations for a population to reach equilibrium (Varvio et al., 1986; Zellmer \& Knowles, 2009). This conclusion is further supported by the results of the analyses of the Meramec River only dataset; see discussion below.

The interpretation of the observed genetic signature in the Volga River only dataset is consistent with other landscape genetic studies of $E$. caeruleum. A recent study utilized microsatellite data to understand the spatial distribution of genetic diversity of the rainbow darter in tributaries of the upper Mississippi River basin in northeast Iowa (Davis et al., 2015). The analyses revealed a single genetic population and no evidence of significant population subdivision despite the large geographic distance separating local populations. The population of rainbow darters in this region were genetically diverse, but the diversity was evenly distributed across the landscape suggesting extensive gene flow and connectivity among population across the landscape. After considering the life history and habitat requirements of the rainbow darter and the glacial history of the region, they concluded that the best explanation was historical events overwhelmed the observed genetic signature and the data were unable to detect the influence of contemporary processes (Davis et al., 2015). Although this study came to a similar conclusion, the use of microsatellite DNA markers presumably limited the resolution of the genetic data. The genome-wide SNP data utilized in this study were able to reveal fine-scale population substructure that was not observed in Davis et al. (2015). Haponski et al. (2009) observed similar patterns of genetic variation in E. caeruleum populations in glaciated regions of the Lake Erie and the Ohio River basins east of the Mississippi River.

\subsection{Adherence to the stream hierarchy model}

In stark contrast, the analyses of the Meramec River only dataset revealed a spatial distribution of genetic diversity that is structured in an upstream to downstream pattern that corresponds to the stream hierarchy model. There was evidence of a strong correlation of genetic differentiation with river distance (Figure $5 \mathrm{~B}$ ) that was further supported by the pattern observed in the DAPC (Figure 4C) and the pairwise $\mathrm{F}_{\mathrm{ST}}$ values (Table S3B). There is greater genetic diversity (Table 1C) observed in the Meramec River than in the northern Volga River, which is best explained by differences among individuals within populations (Table $2 \mathrm{C}$ ). There were also fewer genetic clusters observed (Figure 3C) suggesting greater connectivity among the local populations.

The adherence to the stream hierarchy model observed in the Meramec River only dataset suggests that habitat in the region remained relatively undisturbed by the climatic changes of the Quaternary period. The river valleys of the Ozark Plateau are older and entrenched, and lack sedimentation levels found within the glacial drift plains in the North (Forman et al. 1992; Galloway et al., 2011). The lotic habitat of these rivers 
also contains nearly continuous suitable habitat for the rainbow darter. Taking these factors together, the best explanation for the pattern observed is that life history of E. caeruleum, including high site fidelity and diet preferences of the species, shaped the spatial distribution of genetic diversity. Rainbow darters and their preferred prey have a preference for fast-moving riffle habitats and are less prevalent in deeper slow-moving pools (Hicks \& Servos, 2017; Mueller et al., 2020). Therefore, the riffle-run-pool structure of streams may represent a permeable barrier to migratory movement further contributing to the observed pattern.

\section{5 | CONCLUSIONS}

The results of this study highlight the necessity for understanding the geologic and climatic history of a region and the life history of an organism when interpreting population genomic patterns. The same species in different environments can have very different patterns of genetic diversity due to the dynamic nature of the landscape. This is especially true in riverine environments. In riverscapes where aquatic habitats have been stable over long periods of time, the spatial distribution of genetic diversity will likely fit expectations of models based on the life history of the organism and patterns of the drainage network. However, in riverscapes that are impacted, the observed patterns may not be obvious and are often difficult to interpret based on contemporary processes. In addition, these genetic signatures may persist for a long period of time due to the effects of a time-lag. When interpreting genetic data for conservation of species in glaciated environments, it is imperative that these factors are taken into consideration. A failure to do so may result in an inaccurate interpretation and mislead conservation efforts.

\section{ACKNOWLEDGEMENTS}

We thank J. Abels, M. Borsh, C. Knight, M. North and J. Parks for help collecting specimens. We also thank J. DeGroote and P. Carvalho De Castro at UNI GeoTREE for generating the maps. Finally, we thank J. Abels, M. Borsh, J. Demastes, R. McDonnell and M. Myers for helpful comments on the manuscript.

\section{AUTHOR CONTRIBUTIONS}

J.M.L. and P.B.B. designed the study, provided the funding, performed fieldwork to collect samples, collected and analyzed the data and wrote the manuscript. T.G. participated in collection and analyses of the data and edited the manuscript.

\section{DATA AVAILABILITY STATEMENT}

The sequence data were deposited in the NCBI SRA database under BioProject ID XXXXXXX.

\section{REFERENCES}

Allendorf, F. W., \& Luikart, G. (2007). Conservation and the genetics of populations . London, UK: Blackwell.

Anderson, W. I. (1998). Iowa's geological past: Three billion years of earth history . Iowa City, IA: University of Iowa Press.

Andrews, K.R., Good, J.M., Miller, M.R., Luikart, G., \& Hohenlohe, P.A. (2016). Harnessing the power of RADseq for ecological and evolutionary genomics. Nature Reviews Genetics, 17 (2), 81-92.

Berendzen, P. B., Simons, A. M., \& Wood, R. M. (2003). Phylogeography of the northern hogsucker, Hypentelium nigricans (Teleostei: Cypriniformes): Genetic evidence for the existence of the ancient Teays River. Journal of Biogeography, 30 (8), 1139-1152.

Berendzen, P. B., Simons, A. M., Wood, R. M., Dowling, T. E., \& Secor, C. L. (2008). Recovering cryptic diversity and ancient drainage patterns in eastern North America: Historical biogeography of the Notropis rubellus species group (Teleostei: Cypriniformes). Molecular Phylogenetics and Evolution, 46 (2), 721-737.

Berendzen, P. B., Dugan, J. F., \& Gamble, T. (2010). Post-glacial expansion into the Paleozoic Plateau: Evidence of an Ozarkian refugium for the Ozark minnow Notropis nubilus (Teleostei: Cypriniformes).Journal of Fish Biology, 77 (5), 1114-1136. 
Bettis III, E. A. (1989). Late Quaternary history of the Iowa River Valley in the Coralville Lake area in. Plocher, OW, Geologic Reconnaissance of the Coralville Lake area: Geological Society of Iowa Guidebook, 51, 93-100.

Brauer, C. J., Unmack, P. J., Smith, S., Bernatchez, L., \& Beheregaray, L. B. (2018). On the roles of landscape heterogeneity and environmental variation in determining population genomic structure in a dendritic system. Molecular Ecology , 27 (17), 3484-3497.

Burr, B. M., \& Page, L. M. (1986). Zoogeography of fishes of the lower Ohio-upper Mississippi basin. In C. H. Hocutt \& E. O. Wiley (Eds.), The zoogeography of North American freshwater fishes (pp. 287-324). New York, NY: John Wiley \& Sons.

Catchen, J. M., Amores, A., Hohenlohe, P., Cresko, W., \& Postlethwait, J. H. (2011). Stacks: building and genotyping loci de novo from short-read sequences. G3: Genes| Genomes| Genetics, 1 (3), 171-182.

Catchen, J., Hohenlohe, P. A., Bassham, S., Amores, A., \& Cresko, W. A. (2013). Stacks: An analysis tool set for population genomics. Molecular Ecology, 22 (11), 3124-3140.

Chhatre, V. E. (2019). Distruct v2.3, A modified cluster membership plotting script [Computer software]. Retrieved from http://distruct2.popgen.org

Cupples, W., \& Arsdale, R. V. (2014). The Preglacial "Pliocene" Mississippi River. The Journal of Geology, 122 (1), 1-15.

Davis, C. D., Epps, C. W., Flitcroft, R. L., \& Banks, M. A. (2018). Refining and defining riverscape genetics: How rivers influence population genetic structure. Wiley Interdisciplinary Reviews: Water, 5 (2), e1269.

Davis, D. J., Wieman, A. C., \& Berendzen, P. B. (2015). The influence of historical and contemporary landscape variables on the spatial genetic structure of the rainbow darter (Etheostoma caeruleum ) in tributaries of the upper Mississippi River. Conservation Genetics , 16 (1), 167-179.

Dray, S., \& Dufour, A. B. (2007). The ade4 package: implementing the duality diagram for ecologists. Journal of statistical software ,22 (4), 1-20.

Echelle, A. A., Schwemm, M. R., Lang, N. J., Nagle, B. C., Simons, A. M., Unmack, P. J., .. \& Hoagstrom, C. W. (2014). Molecular systematics and historical biogeography of the Nocomis biguttatus species group (Teleostei: Cyprinidae): Nuclear and mitochondrial introgression and a cryptic Ozark species. Molecular Phylogenetics and Evolution, 81, 109-119.

Elfrink, N. M., \& Siemens, M. A. (1998). Quaternary drainage shifts in Missouri . Guidebook for the 45th Annual Field Trip. Association of Missouri Geologists, Farmington, Missouri, 48-49.

Epps, C. W., \& Keyghobadi, N. (2015). Landscape genetics in a changing world: disentangling historical and contemporary influences and inferring change. Molecular Ecology , 24 (24), 6021-6040.

Etter, P. D., Bassham, S., Hohenlohe, P. A., Johnson, E. A., \& Cresko, W. A. (2012). SNP discovery and genotyping for evolutionary genetics using RAD sequencing. In V. Orogogozo \& M. V. Rockman (eds.), Molecular methods for evolutionary genetics (pp. 157-178). Humana Press.

Excoffier, L., \& Lischer, H. E. (2010). Arlequin suite ver 3.5: A new series of programs to perform population genetics analyses under Linux and Windows. Molecular Ecology Resources, 10 (3), 564-567.

Falush, D., Stephens, M., \& Pritchard, J. K. (2007). Inference of population structure using multilocus genotype data: dominant markers and null alleles. Molecular Ecology Notes , 7 (4), 574-578.

Forman, S. L., Bettis, E. A., Kemmis, T. J., \& Miller, B. B. (1992). Chronologic evidence for multiple periods of loess deposition during the Late Pleistocene in the Missouri and Mississippi River Valley, United States: Implications for the activity of the Laurentide ice sheet.Palaeogeography, Palaeoclimatology, Palaeoecology, 93 (1-2), 71-83. 
Galloway, W. E., Whiteaker, T. L., \& Ganey-Curry, P. (2011). History of Cenozoic North American drainage basin evolution, sediment yield, and accumulation in the Gulf of Mexico basin. Geosphere, 7 (4), 938-973.

Gamble, T., Coryell, J., Ezaz, T., Lynch, J., Scantlebury, D. P., \& Zarkower, D. (2015). Restriction SiteAssociated DNA Sequencing (RAD-seq) Reveals an Extraordinary Number of Transitions among Gecko Sex-Determining Systems. Molecular Biology and Evolution,32 (5), 1296-1309.

Goudet, J. (2005). Hierfstat, a package for $\mathrm{r}$ to compute and test hierarchical F-statistics. Molecular Ecology Notes, 5 (1), 184-186.

Haponski, A. E., Bollin, T. L., Jedlicka, M. A., \& Stepien, C. A. (2009). Landscape genetic patterns of the rainbow darterEtheostoma caeruleum : A catchment analysis of mitochondrial DNA sequences and nuclear microsatellites. Journal of Fish Biology, 75 (9), 2244-2268.

Harding, J. M., Burky, A. J., \& Way, C. M. (1998). Habitat Preferences of the Rainbow Darter, Etheostoma caeruleum, with Regard to Microhabitat Velocity Shelters. Copeia, 1998 (4), 988.

Hicks, K. A., \& Servos, M. R. (2017). Site fidelity and movement of a small-bodied fish species, the rainbow darter (Etheostoma caeruleum ): Implications for environmental effects assessment.River Research and Applications, 33 (7), 1016-1025.

Hobbs, H. (1999). Origin of the Driftless Area by subglacial drainage-a new hypothesis. Geological Society of America Special Papers ,337, 93-102.

Hubisz, M. J., Falush, D., Stephens, M., \& Pritchard, J. K. (2009). Inferring weak population structure with the assistance of sample group information. Molecular Ecology Resources , 9 (5), 1322-1332.

Jombart, T. (2008). adegenet: a R package for the multivariate analysis of genetic markers. Bioinformatics , 24 (11), 1403-1405.

Jombart, T., Devillard, S., \& Balloux, F. (2010). Discriminant analysis of principal components: A new method for the analysis of genetically structured populations. BMC Genetics, 11 (1), 94.

Jombart, T., \& Collins, C. (2015). A tutorial for discriminant analysis of principal components (DAPC) using adegenet 2.0. 0. London: Imperial College London, MRC Centre for Outbreak Analysis and Modelling

Knox, J. C. (2007). The Mississippi river system. In A. Gupta (Ed.),Large rivers: geomorphology and management (pp. 145-182). New York, NY: John Wiley \& Sons.

Lischer, H. E., \& Excoffier, L. (2012). PGDSpider: An automated data conversion tool for connecting population genetics and genomics programs. Bioinformatics, 28 (2), 298-299.

Lowe, J. J., \& Walker, M. J. (2014). Reconstructing quaternary environments. Routledge.

Meffe, G. K., \& Vrijenhoek, R. C. (1988). Conservation genetics in the management of desert fishes. Conservation Biology, 2 (2), 157-169.

Menzel, B. W. (1983). Agricultural management practices and the integrity of instream biological habitat. Agricultural Management and Water Quality. Iowa State University Press, Ames Iowa. 1983. p 305-329, 3 fig, 4 tab, 98 ref. Iowa Agriculture and Home Economics Experiment Station Project , (2410).

Mueller, S. J., Bradshaw-Wilson, C., \& Stauffer, J. R., Jr. (2020). Dietary variability of the rainbow darter (Etheostoma caeruleum ) in Northwestern Pennsylvania. Northeastern Naturalist, 27 (2), 263-271.

Muhs, D. R., Bettis, E. A., \& Skipp, G. L. (2018). Geochemistry and mineralogy of late Quaternary loess in the upper Mississippi River valley, USA: Provenance and correlation with Laurentide Ice Sheet history. Quaternary Science Reviews, 187, 235-269. 
Near, T. J., Page, L. M., \& Mayden, R. L. (2001). Intraspecific phylogeography of Percina evides (Percidae: Etheostomatinae): An additional test of the Central Highlands pre-Pleistocene vicariance hypothesis. Molecular Ecology, 10 (9), 2235-2240.

Page LM (2000) Etheostomatinae. In: Craig JF (ed) Percid fishes: systematics, ecology, and exploitation (pp. 225-253). Chicago, IL: University of Chicago Press.

Paris, J. R., Stevens, J. R., \& Catchen, J. M. (2017). Lost in parameter space: A road map for stacks. Methods in Ecology and Evolution, 8 (10), 1360-1373.

Pflieger, W. L. (1975). The fishes of Missouri . Missouri Department of Conservation.

Pina-Martins, F., Silva, D. N., Fino, J., \& Paulo, O. S. (2017). Structure_threader: An improved method for automation and parallelization of programs structure, fastStructure and MavericK on multicore CPU systems. Molecular Ecology Resources, 17 (6).

Pritchard, J. K., Stephens, M., \& Donnelly, P. (2000). Inference of population structure using multilocus genotype data. Genetics ,155 (2), 945-959.

R Development Core Team. (2020). R: A language and environment for statistical computing (Version 3.6.3) [Computer software]. Retrieved from https://www.r-project.org/

Raj, A., Stephens, M., \& Pritchard, J. K. (2014). FastSTRUCTURE: Variational Inference of Population Structure in Large SNP Data Sets.Genetics, 197 (2), 573-589.

Ray, J. M., Wood, R. M., \& Simons, A. M. (2006). Phylogeography and post-glacial colonization patterns of the rainbow darter,Etheostoma caeruleum (Teleostei: Percidae). Journal of Biogeography, 33 (9), 1550-1558.

Rochette, N. C., \& Catchen, J. M. (2017). Deriving genotypes from RAD-seq short-read data using Stacks. Nature Protocols,12 (12), 2640-2659.

Rochette, N. C., Rivera-Colón, A. G., \& Catchen, J. M. (2019). Stacks 2: Analytical methods for paired-end sequencing improve RADseq-based population genomics. Molecular Ecology, 28 (21), 4737-4754.

Rohland, N., \& Reich, D. (2012). Cost-effective, high-throughput DNA sequencing libraries for multiplexed target capture. Genome Research, 22 (5), 939-946.

Rousset, F. (1997). Genetic differentiation and estimation of gene flow from F-statistics under isolation by distance. Genetics ,145 (4), 1219-1228.

Strange, R. M., \& Burr, B. M. (1997). Intraspecific Phylogeography of North American Highland Fishes: A Test of the Pleistocene Vicariance Hypothesis. Evolution, 51 (3), 885.

Thornbury, W. D. (1965). Regional geomorphology of the United States . New York, NY: John Wiley \& Sons.

Tonnis, B. D. (2006). Microsatellite DNA markers for the rainbow darter,Etheostoma caeruleum (Percidae), and their potential utility for other darter species. Molecular Ecology Notes, 6 (1), 230-232.

Varvio, S. L., Chakraborty, R., \& Nei, M. (1986). Genetic variation in subdivided populations and conservation genetics. Heredity, 57 (2), 189-198.

Weir, B. S., \& Cockerham, C. C. (1984). Estimating F-statistics for the analysis of population structure. Evolution, 38 (6), 1358.

Whitlock, M. C., \& McCauley, D. E. (1990). Some population genetic consequences of colony formation and extinction: genetic correlations within founding groups. Evolution , 44 (7), 1717-1724.

Young, F. J., \& Hammer, R. D. (2000). Soil-Landform Relationships on a Loess-Mantled Upland Landscape in Missouri. Soil Science Society of America Journal, 64 (4), 1443-1454. 
Zellmer, A. J., \& Knowles, L. L. (2009). Disentangling the effects of historic vs. contemporary landscape structure on population genetic divergence. Molecular Ecology , 18 (17), 3593-3602.

Figure 1 Map of the approximated limits of pre-Illinoian (2.5 - 0.5 million years ago), Illinoian (300,000 140,000 years ago), and Wisconsinan (19,000 - 10,500 years ago) glacial advancements in the central portion of North America.

Figure 2 The approximate geographic distribution of the rainbow darter (Etheostoma caeruleum ) in eastern North America: spatial data obtained from NatureServe (2013). Insets indicate sampling localities within the Volga and Meramec rivers. Arrows indicate direction of flow of water. Image of a male rainbow darter.

FIGURE 3 Estimated membership coefficients based on admixture analyses. Vertical axis indicates membership coefficient and the horizontal axis indicates the locality for each individual. A. Combined river dataset for $\mathrm{K}=4$, B. Volga-only dataset for $\mathrm{K}=4$ and $\mathrm{C}$. Meramec-only dataset for $\mathrm{K}=3$.

FIGURE 4 Scatterplots from discriminant analysis of principal components (DAPC) with individuals designated by locality. Eigenvalues of the analyses are displayed as insets. A. Combined river dataset. B. Volga-only dataset. C. Meramec-only dataset.

FIGURE 5 Scatter plots of the Mantel tests for isolation by distance using in-river distances with the regression line (red) and Lowess smoothed regression / trend line (dashed blue). A. Volga-only dataset (p $\left.=0.259, \mathrm{R}^{2}=0.245\right)$ and B. Meramec-only dataset $\left(\mathrm{p}=0.015, \mathrm{R}^{2}=0.904\right)$.

\section{Hosted file}

Fig1.pdf available at https://authorea.com/users/418030/articles/524913-comparativeriverscape-genomics-of-the-rainbow-darter-etheostoma-caeruleum-in-glaciated-andunglaciated-environments

\section{Hosted file}

Fig2.pdf available at https://authorea.com/users/418030/articles/524913-comparativeriverscape-genomics-of-the-rainbow-darter-etheostoma-caeruleum-in-glaciated-andunglaciated-environments

A.

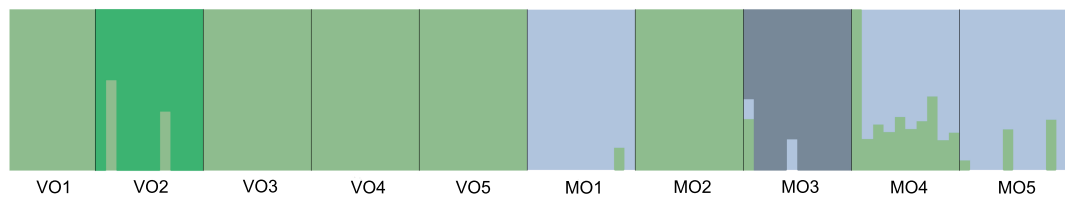

B.

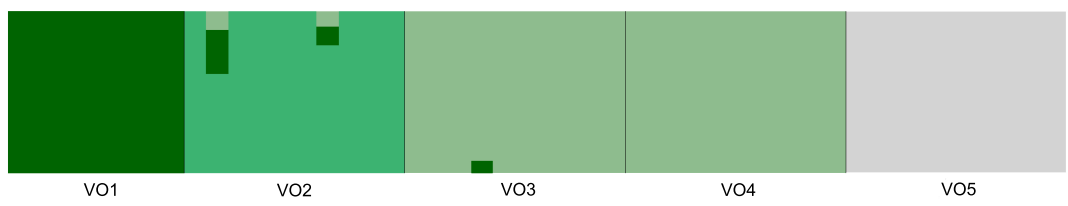

C.

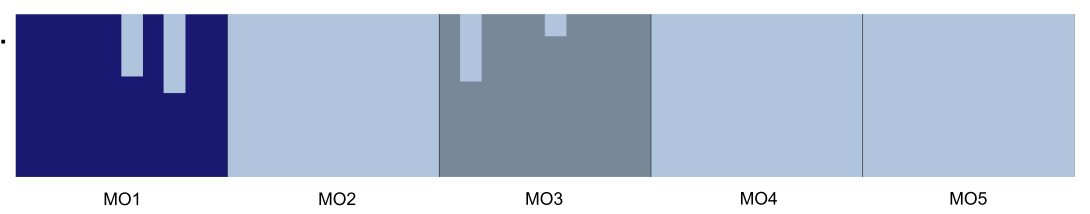




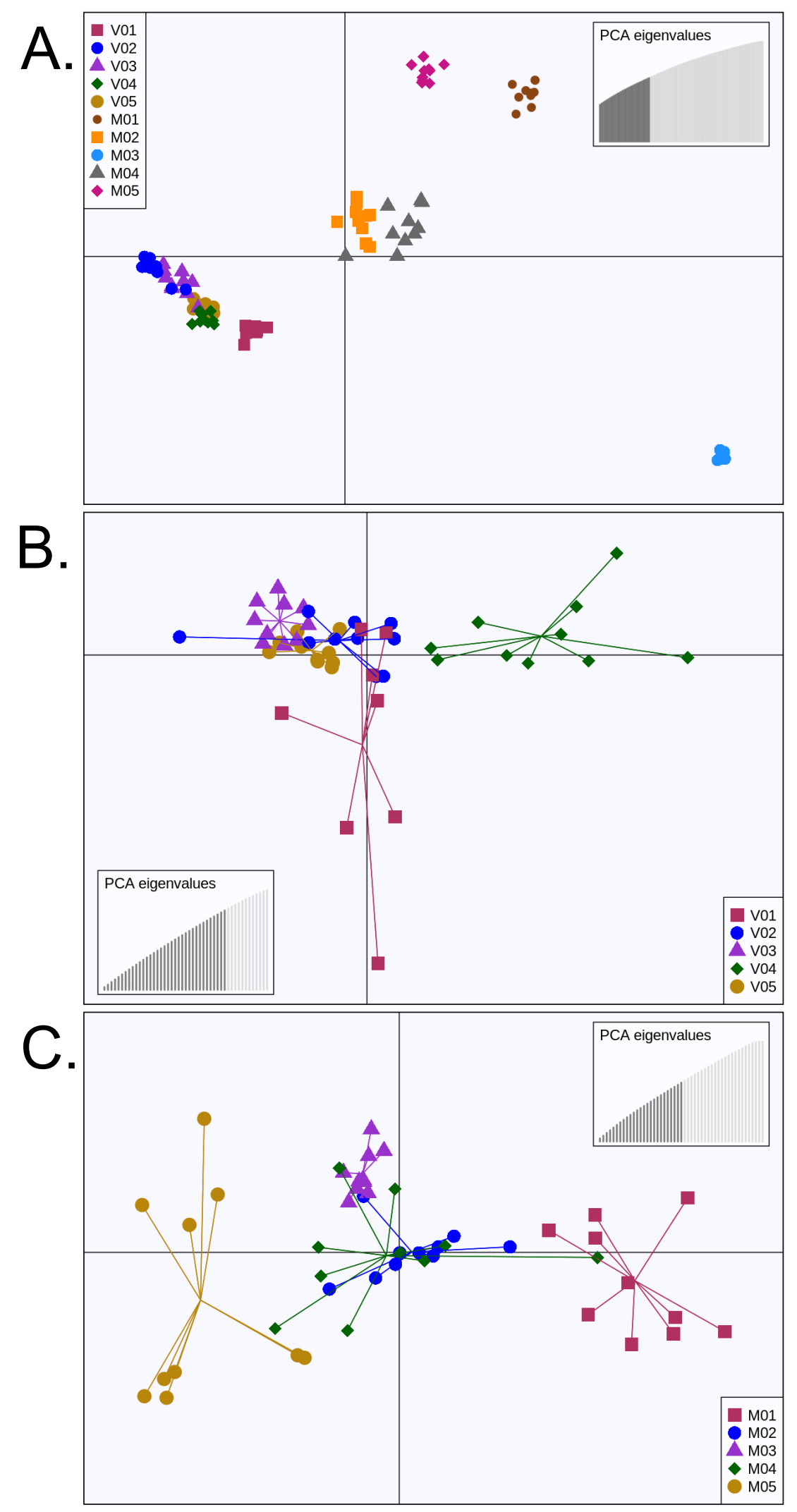




\section{A. Volga River}

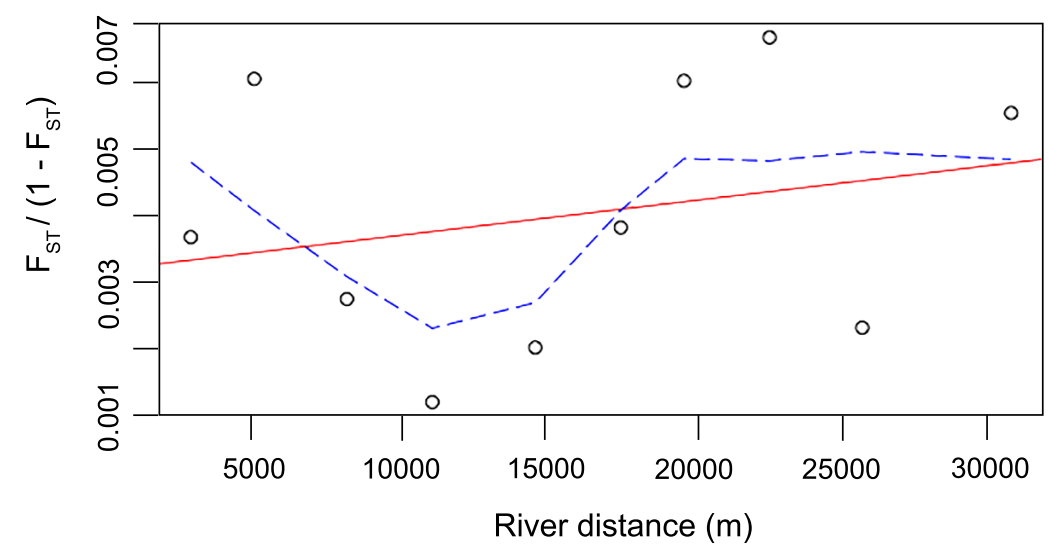

\section{B. Meramec River}

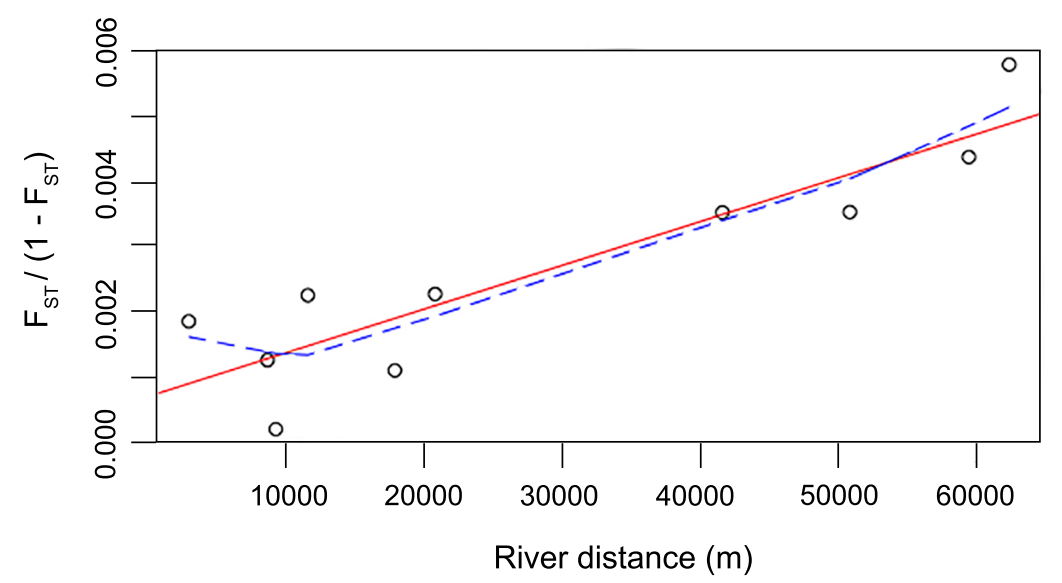

\section{Hosted file}

Table 1.docx available at https://authorea.com/users/418030/articles/524913-comparativeriverscape-genomics-of-the-rainbow-darter-etheostoma-caeruleum-in-glaciated-andunglaciated-environments

\section{Hosted file}

Table 2.docx available at https://authorea.com/users/418030/articles/524913-comparativeriverscape-genomics-of-the-rainbow-darter-etheostoma-caeruleum-in-glaciated-andunglaciated-environments 